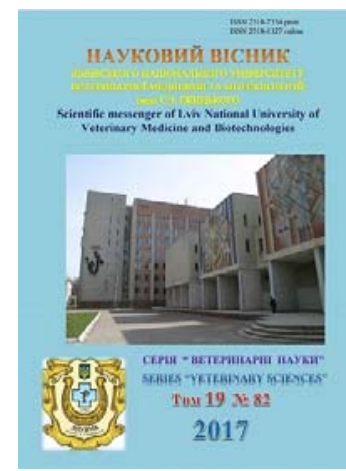

Науковий вісник Львівського національного університету ветеринарної медицини та біотехнологій імені С.З. Гжицького

Scientific Messenger of Lviv National University of Veterinary Medicine and Biotechnologies

doi:10.15421/nvlvet8205

ISSN 2518-7554 print

ISSN 2518-1327 online

http://nvlvet.com.ua/

УДК 619:616.64/.69:636-7

\title{
Експрес-оцінка репродуктивної здатності псів в умовах розплідника
}

\author{
Т.В. Воронов, П.М. Скляров \\ tarasvetvoronov@gmail.com, skliarov.p.m@dsau.dp.ua \\ Дніпровський державний аграрно-економічний університет, \\ вул. С. Сфремова, 25, м. Дніпро, 49000, Украӥна
}

\begin{abstract}
Розроблено експрес-оцінку репродуктивної здатності псів, яка передбачає проведення загального клінічного дослідження самиів, обстеження стану сечостатевої системи, визначення прояву статевих рефлексів та виведення спермограми. Одержані результати розподіляються за шкалою: «Д》 (добре) - патологічних змін не виявлено, усі показники гомеостазу $i$ спермограми в межах норми. Плідника можна використовувати без обмежень; «3» (задовільно) - незначні відхилення від норми, що мають несуттєвий вплив на організм і частково знижують репродуктивний потенціал пса. Самиа допускають до відтворення з обмеженням за ретельного контролю його репродуктивного використання; «Н» (незадовільно) - патологічний стан організму, гіпо- чи імпотенція. До розведення не допускається.

За результатами досліджень визначено, що експрес-оцінка репродуктивної здатності псів дозволяє провести швидку та досить об'єктивну оцінку репродуктивного потенціалу великої кількості псів за обмежений термін, виявити неплідних тварин, розробити та здійснити необхідні превентивні чи лікувальні заходи.

Встановлено, щуо із загальної кількості оцінених псів розплідника «Zvezdnoye schastye» оиінку «добре» отримали 12 псів (або 76\%) і рекомендовані до розведення, 4 - «задовільно» (18\%) і можуть бути допущеними до відтворення з обмеженням за ретельного контролю їх репродуктивного використання, 1 - «незадовільно» (6\%) з рекомендацією провести лікування супутніх патологій та пройти повторний тест через місяиь.

Ключові слова: андрологічна диспансеризачія, пси, статеві рефлекси, патології відтворення, зниження відтворної здатності, експрес-діагностика.
\end{abstract}

\section{Экспресс-оценка репродуктивной способности кобелей в условиях питомника}

\author{
Т.В. Воронов, П.Н. Скляров \\ tarasvetvoronov@gmail.com, skliarov.p.m@dsau.dp.ua
}

Днепровский государственный аграрно-экономический университет, ул. С. Ефремова, 25, г. Днепр, 49000, Украина

\begin{abstract}
Разработана экспресс-оценка репродуктивной способности собак, которая предусматривает проведение общего клинического исследования самиов, обследование состояния мочеполовой системы, определение проявления половых рефлексов и выведение спермограммы. Полученные результаты распределяются по шкале: «Х» (хорочо) - патологических изменений не выявлено, все показатели гомеостаза и спермограммы в пределах нормы. Производителя можно использовать без ограничений; «У» (удовлетворительно) - незначительные отклонения от нормы, имеютие несущественное влияние на организм и частично снижсают репродуктивный потенциал пса. Самиа допускают к воспроизводству с ограничением при тщзательном контроле его репродуктивного использования; «Н» (неудовлетворительно) - патологическое состояние организма, гипо- или импотенция. К разведению не допускается.

По результатам исследований установлено, что экспресс-оценка репродуктивной способности собак позволяет провести быструю и достаточно объективную оченку репродуктивного потенциала большого количества кобелей в ограничен-
\end{abstract}

Citation:

Voronov, T., Skliarov, P. (2017). Express evaluation of reproductive capacity of dogs in the conditions of the nursery. Scientific Messenger LNUVMB, 19(82), 21-24. 
ный срок, выявить бесплодных животных, разработать и осуществить необходимые превентивные или лечебные мероприятия.

Установлено, что из общего количества оцененных собак питомника «Zvezdnoye schastye» оценку «хорошо» получили 12 собак (или 76\%) и рекомендованы к разведению, 4- «удовлетворительно» (18\%) и могут быть допущены к воспроизводству с ограничением при тицательном контроле их репродуктивного использования, 1 - «неудовлетворительно» (6\%) с рекомендацией провести лечение сопутствуюших патологий и пройти повторный тест через месяи.

Ключевье слова: андрологическая диспансеризачия, кобели, половые рефлекси, патологии репродукции, сниљение фертильности, экспресс-диагностика.

\title{
Express evaluation of reproductive capacity of dogs in the conditions of the nursery
}

\author{
T. Voronov, P. Skliarov \\ tarasvetvoronov@gmail.com, skliarov.p.m@dsau.dp.ua \\ Dnipro State Agrarian and Economic University, \\ S. Efremov Str., 25, Dnipro, 49000, Ukraine
}

In recent decades doctors of veterinary medicine have devoted particular attention to dogs and, in particular, to the questions of physiology and pathology of their reproduction. The result is the publication of a significant number of manuals and monographs devoted to the actual issues of diagnosis and treatment of small animal diseases. Little remains the problems of andrological pathology of dogs, while the requirements for quality and number of offspring in high-value breeds of dogs and, consequently, reproductive health dogs. An important direction in solving these issues is the holding of andrological dispensary, which allows to diagnose the form of impotence, to identify the causes, to develop medical and preventive measures. However, in the conditions of large nurseries to study a significant number of dogs in limited time, there is a need for an accelerated, but at the same time, objective assessment of reproductive capacity of males. Proceeding from this, the aim of the work was to validate the method developed by us for express evaluation of the reproductive capacity of dogs in the conditions of a particular nursery.

We have developed an express assessment of the reproductive capacity of dogs, which involves conducting a general clinical trial of males, a survey of the genitourinary system, determining the manifestation of sexual reflexes and the withdrawal of spermograms. The obtained results of research were distributed on a scale: "G» (good) - pathological changes were not found, all indicators of homeostasis and spermograms within the norm. The pedigree can be used without restrictions; "S» (satisfactory) - slight deviations from the norm, which have a minor effect on the body and partly reduce the reproductive potential of the dog. The herb is allowed to reproduce with a restriction on the careful control of its reproductive use; "U» (unsatisfactory) - a pathological state of the body, hypotension or impotence. Breeding is not allowed.

According to the results of the research, it was determined that express assessment of the reproductive capacity of the dogs makes it possible to carry out a quick and fairly objective assessment of the reproductive potential of a large number of dogs for a limited period, to identify diseased animals, to develop and implement the necessary preventive or curative measures.

It was established that from the total number of evaluated dogs of the "Zvezdnoye schastye» nursery, 12 dogs (or 76\%) were rated "good» and recommended for breeding, 4 - were «satisfactorily» (18\%) and could be allowed to be restrained with careful control their reproductive use, 1 - «unsatisfactory» (6\%) with the recommendation to carry out the treatment of concomitant pathologies and pass a repeat test in a month.

Key words: andrological examination, dog males, sexual reflexes, reproductive pathologies, fertility decline, express diagnostics.

\section{Вступ}

Останніми десятиріччями в Україні, як і в інших країнах, особливу увагу лікарі ветеринарної медицини відводять собакам і зокрема питанням фізіології та патології їх розмноження (Simpson et al., 2005; Ingljend, 2012; Fel'dman and Nel'son, 2008; Djul'ger and Djul'ger, 2017; Berezovs'kij et al., 2017).

Результатом цього є видання значної кількості посібників і монографій, присвячених актуальним питанням діагностики та лікування хвороб дрібних тварин (Fasolja, 2008).

Малодослідженими залишаються проблеми андрологічної патології псів (Fedotov, 2014), в той час коли збільшилися вимоги до якості та кількості потомства у високоцінних порід собак і відповідно репродуктивного здоров'я псів.

Пса вважаюсь неплідним у тому випадку, якщо після декількох в'язок із здоровою самкою не отримали потомства або взагалі пес не може пов'язати суку. Власники племінної тварини звертаються до спеціалі- стів ветеринарної медицини лише коли кілька в'язок недоотримують кількість потомства, що є нормою для певної породи.

Для постановки діагнозу «імпотенція», важливо знайти першопричину, проаналізувавши анамнез, результати клінічних та додаткових досліджень, особливо важливим дослідженням є виведення спермограми та визначення рівня статевих гормонів. Тільки детальний аналіз надасть змогу призначити ефективне лікування. Детальні відомості з історії хвороби тварини можуть роз'яснити причини зниження плодючості, так деякі медикаменти викликають тимчасову або постійну неплідність. Тому така специфікація фахівців ветеринарної медицини, як андролог має своє місце в загальній репродуктології та повсякденній практиці.

Важливим напрямом у вирішенні цих питань $\epsilon$ проведення андрологічної диспансеризації (Perleckaja and Shestakova, 2017), що дозволяє діагностувати форму імпотенції, встановити причини, розробити лікувальні і профілактичні заходи. 
Однак, за умов крупних розплідників для дослідження значного поголів'я псів в обмежені терміни виникає необхідність прискореної, але у той же час об'єктивної оцінки репродуктивної здатності самців.

Мета роботи - апробувати розроблену нами методику експрес-оцінки репродуктивної здатності псів в умовах конкретного розплідника.

\section{Матеріал і методи досліджень}

Робота виконувалася в умовах розплідника «Zvezdnoye schastye» м. Кривий Ріг Дніпропетровської області. При проведенні досліджень користувалися загальноклінічними, а також спеціальними методами діагностики. За діагностики репродуктивної функції псів необхідно виключити наявність хвороб репродуктивної сфери, що мають прямий вплив на спермогенез та фертильність.

За даними анамнезу уточняються кількість в'язок, кількість продуктивних в'язок, має значення кількість отриманих цуценят порівнюючи з нормою по породі, їх здоров'я, наявність породних вад розвитку чи забарвлення.

При клінічному дослідженні у плідника в першу чергу повинні бути виключені інфекційні та інвазійні хвороби, які можуть бути передані самиці чи цуценяті. Стан органів сечостатевої системи досліджували загально клінічними та спеціальними методами. У псів середніх та великих порід стан простати визначали через пряму кишку, у дрібних, за допомогою ультразвукового дослідження.

Прояв статевих рефлексів досліджували в присутності тічної суки.

До комплексного оцінювання загального стану тварини входило визначення гематологічних та біохімічних показників крові.

Для оцінки якості сперми іï одержували методом мастурбації, досліджуючи усі три фракції сперми окремо з визначенням органолептичних (об'єм, колір, запах, консистенція) та мікроскопічних (активність сперміїв, їх концентрацію, відсоток патологічних форм) показників.

\section{Результати та їх обговорення}

У розпліднику одночасно перебувають 103 собаки представники різних порід (йоркширський тер'єр, німецький шпіц, чіхуахуа, вест-хайленд-вайт-тер'єр , шарпей, французький бульдог, бігль).

Загальна кількість псів - 17, навантаження на пса не більше 5 сук, з еякуляцією не частіше, ніж одна раз на три дні.

Одержані результати досліджень інтерпретували 3 використанням розробленої нами експрес-оцінки репродуктивної здатності псів, яка передбачає проведення загального клінічного дослідження самців, обстеження стану сечостатевої системи, визначення прояву статевих рефлексів та виведення спермограми.

Визначені під час дослідження показники розподілялися за шкалою:

- «Д» (добре) - патологічних змін не виявлено, усі показники гомеостазу і спермограми в ме- жах норми. Плідника можна використовувати без обмежень.

- «З» (задовільно) - незначні відхилення від норми, що мають несуттєвий вплив на організм і частково знижують репродуктивний потенціал пса. Плідника допускають до відтворення з обмеженням за ретельного контролю його репродуктивного використання.

- «Н» (незадовільно) - патологічний стан організму, гіпо- чи імпотенція. До розведення не допускається.

Результати експрес-оцінки репродуктивної здатності псів розплідника «Zvezdnoye schastye» наведено у табл. 1 .

Як свідчать одержані дані, із сімнадцяти досліджених псів оцінку «добре» за всіма оцінюваними параметрами одержали дванадцять псів. 3 інших п'яти псів, чотири оцінку «задовільно» отримали за одним параметром (по одному - за загальний клінічний стан та спермограму, два - прояв статевих рефлексів), ще один - відразу за чотирма параметрами (загальний клінічний стан, стан сечостатевої системи, спермограма, додаткові методи дослідження) за що отримав оцінку «незадовільно».

Узагальнені результати експрес-оцінки репродуктивної здатності псів розплідника «Zvezdnoye schastye» наведено на рис. 1.

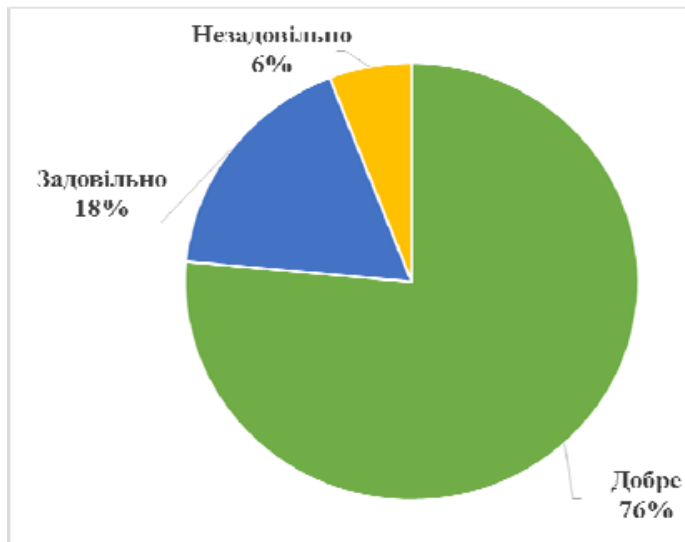

\section{Рис. 1. Узагальнені результати експрес-оцінки репродуктивної здатності псів розплідника «Zvezdnoye schastye»}

Тобто, із загальної кількості оцінених псів розплідника «Zvezdnoye schastye» оцінку «добре» отримали 12 псів (або 76\%), 4 - «задовільно» (18\%), 1 - «незадовільно» $(6 \%)$.

\section{Висновки}

1. Визначено, що експрес-оцінка репродуктивної здатності псів дозволяє провести швидку та досить об'єктивну оцінку репродуктивного потенціалу великої кількості псів за обмежений термін, виявити хворих тварин, розробити та здійснити необхідні превентивні чи лікувальні заходи. 
Табличя 1

Результати експрес-оцінки репродуктивної здатності псів розплідника «Zvezdnoye schastye»

\begin{tabular}{|c|c|c|c|c|c|c|c|c|}
\hline $\begin{array}{l}\text { № } \\
\text { 3/П }\end{array}$ & Порода & $\begin{array}{l}\text { Вік, } \\
\text { років }\end{array}$ & $\begin{array}{l}\text { Загальний } \\
\text { клінічний } \\
\text { стан }\end{array}$ & $\begin{array}{c}\text { Стан сечостате- } \\
\text { вої системи }\end{array}$ & $\begin{array}{c}\text { Прояв стате- } \\
\text { вих рефлек- } \\
\text { сів }\end{array}$ & $\begin{array}{l}\text { Спермо- } \\
\text { грама }\end{array}$ & $\begin{array}{c}\text { Додаткові } \\
\text { методи дослі- } \\
\text { дження }\end{array}$ & $\begin{array}{c}\text { Загальна } \\
\text { оцінка } \\
\text { плідника }\end{array}$ \\
\hline 1 & 2 & 3 & 4 & 5 & 6 & 7 & 8 & 9 \\
\hline 1 & Шар-пей & 3 & Д & Д & Д & Д & Д & Д \\
\hline 2 & $\begin{array}{l}\text { Французький } \\
\text { бульдог }\end{array}$ & 2 & Д & Д & Д & Д & Д & Д \\
\hline 3 & $\begin{array}{l}\text { Французький } \\
\text { бульдог }\end{array}$ & 6 & $\begin{array}{c}3 \\
\text { цистит }\end{array}$ & $\begin{array}{c}3 \\
\text { хронічний } \\
\text { цистит }\end{array}$ & Д & $\begin{array}{c}3 \\
\text { поодинокі } \\
\text { лейкоцити }\end{array}$ & $\begin{array}{c}\mathrm{H} \\
\text { лейкоцит-урія, } \\
\text { протеїнурія }\end{array}$ & $\mathrm{H}$ \\
\hline 4 & $\begin{array}{l}\text { Вест-хайленд- } \\
\text { вайт-тер'єр }\end{array}$ & 2 & Д & Д & Д & Д & Д & Д \\
\hline 5 & Йоркшир-тер'єр & 2 & Д & Д & $\begin{array}{c}3 \\
\text { гіпо- } \\
\text { потенція }\end{array}$ & Д & Д & 3 \\
\hline 6 & Йоркшир-тер’єр & 5 & Д & Д & Д & 3 & Д & Д \\
\hline 7 & Йоркшир-тер'єр & 4 & Д & Д & $\begin{array}{c}3 \\
\text { гіпо- } \\
\text { потенція }\end{array}$ & Д & Д & 3 \\
\hline 8 & Йоркшир-тер'єр & 3 & Д & Д & Д & Д & Д & Д \\
\hline 9 & $\begin{array}{l}\text { Померанський } \\
\text { шпі }\end{array}$ & 2 & Д & Д & Д & Д & Д & Д \\
\hline 10 & $\begin{array}{l}\text { Померанський } \\
\text { шпіц }\end{array}$ & 3 & Д & Д & Д & Д & Д & Д \\
\hline 11 & $\begin{array}{l}\text { Померанський } \\
\text { шпіц }\end{array}$ & 5 & Д & Д & Д & Д & Д & Д \\
\hline 12 & $\begin{array}{l}\text { Померанський } \\
\text { шпіц }\end{array}$ & 5 & Д & Д & Д & $\begin{array}{c}3 \\
\text { знижена } \\
\text { активність } \\
\text { сперміїв }\end{array}$ & Д & 3 \\
\hline 13 & Чихуахуа & 6 & $\begin{array}{c}3 \\
\text { пародонтит }\end{array}$ & Д & Д & Д & Д & Д \\
\hline 14 & Чихуахуа & 3 & Д & Д & Д & Д & Д & Д \\
\hline 15 & Чихуахуа & 2 & Д & Д & Д & Д & Д & Д \\
\hline 16 & Чихуахуа & 3 & Д & Д & Д & Д & Д & Д \\
\hline 17 & Чихуахуа & 4 & Д & Д & Д & Д & Д & Д \\
\hline
\end{tabular}

2. Встановлено, що із загальної кількості оцінених псів розплідника «Zvezdnoye schastye» оцінку «добре» отримали 12 псів (або 76\%) і рекомендовані до розведення, 4 - «задовільно» (18\%) і можуть бути допущеними до відтворення 3 обмеженням за ретельного контролю їх репродуктивного використання, 1 - «незадовільно» (6\%) з рекомендацією провести лікування супутніх патологій та пройти повторний тест через місяць.

Перспективи подальших досліджень. Наші подальші дослідження будуть спрямовані на розробку комплексної андрологічної оцінки псів 3 розробкою деталізованих алгоритмів оцінки репродуктивної здатності самців.

\section{Бібліографічні посилання}

Djul'ger, G.P. Djul'ger, P.G. (2017). Fiziologija razmnozhenija i reproduktivnaja patologija sobak. Sankt-Peterburg: Lan' (in Russian).

Ingljend, G. (2012). Akusherstvo i ginekologija sobak. 2e izd. Moskva: Akvarium-Print (in Russian).

Perleckaja, O.V., Shestakova, A.N. (2017). Andrologicheskaja dispanserizacija kobelej $\mathrm{v}$ uslovijah kinologicheskogo centra. Veterinarnyj vrach. 1, 42-46 (in Russian).

Simpson, Dzh., Inglanda, G., Harvi, M. (2005). Rukovodstvo po reprodukcii i neonatalogii sobak $\mathrm{i}$ koshek. Moskva: Sofion (in Russian).

Fasolja, V.P. (2008). Dispanserizacija sobak sluzhbovih porid : avtoref. dis. ... d-ra vet. nauk: 16.00.01; Bilocerkiv. nac. agrar. un-t. Bila Cerkva, 38 (in Ukrainian).

Fedotov, S.V. (2014). Sovershenstvovanie reprodukcii sluzhebnyh sobak v uslovijah CKS MVD Rossii. Vestnik Altajskogo gosudarstvennogo agrarnogo universiteta. 11(121), 116-120 (in Russian).

Fel'dman, Je., Nel'son, R. (2008). Jendokrinologija i reprodukcija sobak i koshek. Moskva: Sofion (in Russian).

Berezovs'kij, A.V., Harenko, M.I., Homin, S.P. (2017). Fiziologija ta patologija rozmnozhennja dribnih tvarin: navch. pos. 2-e vid., pererob. i dop. Zhitomir: Polissja (in Ukrainian). 